ISSN: 2162-3104 Print/ ISSN: 2166-3750 Online Volume 6, Issue 4 (2016), pp. 1038-1044 (C) Journal of International Students http://jistudents.org/

\title{
Realities and Realizations: Reflections on a Social Work Exchange Program between the United States and China
}

\author{
Jennifer Cullen, Widener University, USA \\ Jolynn L. Haney, Widener University, USA \\ Linda Houser, Widener University, USA \\ Jun Cao, Widener University, USA \\ Xi Mi, Widener University, USA
}

\begin{abstract}
China has a long and complex history of political, economic, and educational shifts that have resulted in and from changing cultural values. Over time, the significance and format of social work education in China has changed, as has the need for professionally educated social workers that can support the ever-evolving social needs of China. To this end, some Chinese schools have begun to partner with schools in the U.S. to support the professionalizing of social work in China. This article presents the reflections of faculty and students involved in an exchange program for Chinese students to study in a U.S.-based master of social work program. Expectations, realities, needs, and recommendations of both faculty and students are discussed.
\end{abstract}

Keywords: cultural exchange programs, international social work education

The social work profession in mainland China has had a turbulent history, affecting social work practice and education in China. Changes to China's economy, and resultant social problems, have led Chinese universities to place greater emphasis on training a new generation of social workers. In a number of cases, Chinese universities have reached out to American universities to learn about U.S. social work practice. The purpose of this paper is to reflect on the first year experiences of faculty and students involved in an educational exchange program between the Chongqing 
Technology and Business University (CTBU) in Chongqing, China and Widener University in Pennsylvania, United States.

\section{History of Social Work and Social Work Education in China}

According to Fang (2013), the history of social work education in China has run parallel to the economic and national changes that have influenced the way social welfare problems have been defined and addressed. Originally, social problems in China were addressed using a "clan-based model," whereby villages and ancestral family organizations managed local social welfare needs (Shu, 2013, p. 18). From the 1920s through the 1940s, social work as a profession expanded, with over twenty universities creating social welfare departments (Liu, Sun, \& Anderson, 2013; Shu, 2013).

After 1952, social work programs, and consequently social work education programs, in China were considered to be "serving the capitalists" (Liu et al., 2013, p. 180); as a result, social work fell out of favor. In the early 1980s, new policies were developed to modernize and industrialize China, leading to a resurgence of social work education programs (Fang, 2013; Feng, 2013; Shu; 2013).

One of the challenges facing social work education programs in China has been "the task of indigenization" (Liu et al., 2013, p. 192). Because the social work profession has waxed and waned in China, current Chinese social work educators lack professional experience and curriculum development experience, and struggle with providing practice opportunities for their students (Lui et al., 2013). Although China has made progress with reestablishing social work education, there remains a need to support China's efforts to create culturally contextual social work programs that incorporate Chinese values.

\section{PROGRAM DESCRIPTION}

\section{Program for Educating Social Work Students}

During the Fall 2015 semester, five CTBU students participated in two distance- learning courses in social work (one policy course and one practice course) from their Chongqing location. As part of the two online introductory courses, two Widener University faculty members traveled to China to provide five days of intensive learning to finalize course content and prepare the students for their Spring semester in the U.S. During the Spring 2016 semester, three CTBU students traveled to the U.S. to participate in three campus-based policy and practice courses at Widener University. The goal of this one-year exchange was to bridge undergraduate coursework taken in China in a variety of substantive areas, with future graduate coursework to be taken in the U.S. in social work. 


\section{Faculty Expectations versus Realities}

Faculty prepared for the Fall 2015 courses according to the format and methods used in their parallel U.S-based courses. Almost immediately the faculty realized there would be difficulties using typical U.S. instruction techniques to educate the CTBU students. For example, although the students were adept at using technology, they were not accustomed to accessing course materials, such as syllabi and assignments, online, to viewing the PowerPoint presentations being used to instruct or to being required to upload papers or participate in message board discussions. In addition, due to the Chinese government's restrictive internet access policies, certain systems of communication and course tools, such as Skype and YouTube videos, were not available. Also, while the students were able to verbally communicate in English, they needed significant support with their writing skills.

Faculty Narrative. We (the U.S. instructors) found the experience of teaching in China to be enlightening. The high value that Chinese citizens place on education was evidenced by the ambitious and extensive coursework taken by our students, by the hospitality and respect shown to us by both students and faculty, and by the level at which students engaged the material we were presenting. We were honored with several meals that included not only high-level CTBU administrators, but also government representatives. Additionally, the students were serious and engaged in the coursework, balancing both their intensive time with us with examinations and lectures in their other courses. The campus and surrounding neighborhood were active with student activities and academic studies from early morning until late into the evening. In fact, during the week, students would attend class with us from $2 \mathrm{pm}$ to $7 \mathrm{pm}$ each day, share meals with us as often as possible, and take us to local sites, all so they could learn more about social work and American culture, as well as practice their English.

Both the policy and practice courses were designed to introduce students to social work as practiced in the U.S., as a precursor to the students' matriculation into a U.S.-based program and internship. Understandably, many of the Western ideologies, values, and theories that predicate social work education in the U.S. were novel to the Chinese students. Also, because many U.S. social welfare policies are based in the history of migration and modernization in the U.S., the students did not have background knowledge and experience to contextualize their new learning. For these reasons, our educational content had to attend not only to the "what" and "how" of U.S. social work, but also to the far more abstract and elusive "why" of U.S. social work.

In addition to course content related issues, the students had different learning style needs than those around which our courses had been 
designed. It became apparent that the students communicated and learned in a collectivist (i.e., shared learning) format, where they communicated both in English and Chinese with one another to interpret and discuss the concepts taught in the class as well as to facilitate the completion of the course assignments. To address this difference, we replaced individual assignments with group assignments. For example, initially the practice course required each student to record a video of themselves conducting an initial client assessment. The assignment was modified so that all students participated in a single role-play that they created to demonstrate interviewing skills, family dynamics issues, and conflict resolution skills. Indeed, during one class session, the students designed and carried out several role plays, alternating the roles of client and social worker.

We made other program adjustments. For example, although graduate social work students at Widener University are required to complete a writing module to learn academic writing skills, faculty determined that weekly group tutoring sessions would provide more individualized writing support for the CTBU students during their time in the U.S. The students faced considerable challenges with completing their writing assignments; assignments that might take their American counterparts one hour to write, could take five or six hours for the CTBU students to complete. In retrospect, writing assignment expectations for the CTBU students may have been unrealistic, given the actual time they needed to acclimate to an American university environment, learn English, and develop formal English writing skills.

\section{Student Expectations versus Realities}

The students expected to learn social work skills within a U.S. context that they could implement in their own country, with the hope of helping China create better policies to support its social welfare needs. The students' expectations centered on becoming more proficient in English and building their social work skills. American life turned out to be very different than what they had expected. They found they were able to spend time with actual clients in the field, role-play social work situations in classes, visit a variety of social service agencies, and meet state politicians.

While some expectations of learning about client interactions and practicing English were realized, the students discovered that studying in the U.S. was very different than in China. In the U.S., the students found they had more freedom to express their thoughts in class and opportunities to collaborate with their classmates. Having limited oral English skills led to some frustration when attempting to understand others and be understood. Two of the female students were roommates, which gave less opportunity to practice English in their dormitory. Because of this, the expectations of 
becoming more proficient in spoken English were not met to their satisfaction.

Student Narratives: The following are excerpts from the students' perspectives:

American life is totally different than I expected. This is a different country and culture from China. I met diverse people, they gave me thoughts about their lifestyle. We shared their experiences and learned how to have a conversation with clients. In class, we used role-play to practice real conversation situations. We helped each other to improve our skills when meeting with clients. I also visited some agencies to learn how organizations work, which really helped me a lot. I went to Harrisburg to advocate for laws that affect social workers, which was a new experience. In China, I did not have opportunities to talk with senators and lawmakers. It was really cool.

Another student wrote:

I feel that when studying in China, people are really concerned about your scores on exams. In China we have different evaluation standards than in the U.S., and our daily behaviors are also important. In China, every class has an exam, and you have to memorize all the theories and write them down. In the U.S., some of our classes don't have final exams. In the U.S., it seems that what professors care about most is whether the student captures the skills or ideas. So while the Chinese way of learning emphasized using exams to evaluate the students, classes in America focus on helping the students to learn and professors use diverse ways to evaluate the students.

In addition, the classes in college are more in China than the U.S. My major was public administration in China, and we used to have eight or more classes every semester, although the social work major students may have more field work, one friend of mine who studied social work also complained about the heavy classwork.

In China we always have more than 60 students in each class, so the professors always lecture and many students don't have the chance to ask questions or answer the professor's questions in class. In the U.S., students are free to speak their own thoughts in class, which would sound incredible in China. Because of the huge number of 
people in one class in China, the professor can't help everyone. The professors don't know many of the students' names.

\section{IMPLICATIONS AND RECOMMENDATIONS}

The general consensus of both faculty and students was that the program was a mutual learning experience. While expectations were different from realties, the experience provided opportunities to learn from one another. The students hoped to learn more policy development and direct social work practice skills, but also used the opportunity to help their U.S. student peers understand the policies and values that guide Chinese systems of welfare management. In terms of learning style, it was clear that cultural elements impacted the learning experience, which required adjusted expectations. The faculty allowed the students to work together on projects and assignments as this enabled them to use their native language and facilitated better understanding of concepts. This collective learning process better suited the collectivist value of Chinese culture than the individualistic drive for grades that is common in the U.S. education system. This adjustment in learning format for projects and assignments also enabled the students to share their values and policy practices in China with the American students thereby enhancing global awareness of social welfare issues.

Based on this initial cultural and educational exchange experience, it seems clear that a successful exchange program requires that both faculty and students be able to adjust their expectations. Three main recommendations for supporting Chinese students in learning at the higher education level emerged. First, course assignments and content delivery may need to be adjusted to accommodate both language and learning style barriers; however, these accommodations need not alter the essential elements of the course, rather they may illuminate underlying assumptions in teaching methods and systems of content delivery that may actually benefit native English-speaking students as well. Second, faculty may need to dedicate more time to explaining and helping international students understand some fundamentals of course content which are often based in assumptions of previous learning. For example, in this program, the essence of social work is predicated on U.S. social welfare and policy development, cultural values and societal needs. These underlying values and needs and concomitant policies will be different when based in Chinese culture. Therefore, educators must make adjustments in delivering content that is based in an assumption of common background, understanding or value bases. Lastly, programs will need to provide support for academic writing, understanding the subtleties of language and social interactions in order to assist students in their adjustment to learning in the U.S. However, it is imperative that educators explain these supports and provide them in a 
manner commensurate with the values of the students so as to avoid any embarrassment or fear of inconvenience that may deter the students from seeking the support they need.

\section{REFERENCES}

Fang, Y. (2013). China's social work education in the face of change. Chinese Education \& Society, 46(6), 28-34. doi:10.2753/CED1061-1932460603

Feng, C. (2013). Thoughts on the professionalization and industrialization of social work in China. Chinese Education \& Society, 46(6), 92-102. doi:10.2753/CED1061-1932460613

Liu, M., Sun, F., \& Anderson, S. (2013). Challenges in social work field education in China: Lessons from the western experience. Social Work Education: The International Journal, 32(2), 179-196. doi:10.1080/02615479.2012.723682

Shu, C. (2013). Significant issues in rebuilding the social work profession in China. Chinese Education and Society, 46(6), 16-27. doi:10.2753/CED10611932460602

JENNIFER CULLEN, PhD, is an assistant professor in the Center for Social Work education at Widener University. Her research focuses on the transition to adulthood including the needs of vulnerable adults, young adults diagnosed with ASD and the professional identity development of social work students. Email: jacullen@widener.edu

JOLYNN L. HANEY, PhD, is an assistant professor in the Center for Social Work Education at Widener University whose research is focused on studying women living on the autism spectrum. She uses a neurodiversity framework to conduct emancipating research, build on strengths, and counter deficit-based disability discourse. Email: jlhaney@widener.edu

LINDA HOUSER, PhD, is an Associate Professor and Doctoral Program Director at Widener University's Center for Social Work Education. Her research focuses on public policy in the areas of employment, caregiving, health, and economic security. Email: ldhouser@mail.widener.edu

JUN CAO and XI MI are students from Chongqing Technology and Business University participating in a cultural and educational exchange program in Widener University's master of social work program.

Manuscript submitted: June 15, 2016

Manuscript revised: September 30, 2016 Accepted for publication: October 15, 2016 $* * *$ 